\title{
FAST DEPOSITED MICROCRYSTALLINE SILICON SOLAR CELLS
}

\author{
P. Torres, J. Meier, U. Kroll, N. Beck, H. Keppner, A. Shah. \\ Institute of Microtechnology, University of Neuchâtel, A.-L. Breguet 2, CH-2000 Neuchâtel, Switzerland \\ U. Malang, University of Konstanz, D-78434 Konstanz, Germany
}

\begin{abstract}
Microcrystalline silicon solar cells with AM 1.5 conversion efficiency above $5 \%$ have been deposited at deposition rates in excess of $10 \AA / s$. This is achieved by VHF-GD at an excitation frequency of $130 \mathrm{MHz}$. By increasing the plasma power at a dilution ratio of $7.5 \%$ silane/(silane+hydrogen) there first appears a morphological transition from a-Si:H to $\mu \mathrm{c}-\mathrm{Si}: \mathrm{H}$ and then an increase in deposition rate. Crystallographic properties and solar cell efficiencies vary thereby in a significant manner.
\end{abstract}

\section{INTRODUCTION}

Hydrogenated microcrystalline silicon ( $\mu \mathrm{c}-\mathrm{Si}: \mathrm{H})$ was introduced some 30 years ago by Veprek and Marecek [1]. Since then, a lot of work has been devoted to investigate doped $\mu \mathrm{c}$-Si:H layers, which are of interest due to their excellent contact properties. Full compatibility with a-Si:H technology allowed indeed their immediate incorporation as contact layers not only in amorphous solar cells but also in TFT's.

On the other hand, undoped $\mu \mathrm{c}-\mathrm{Si}: \mathrm{H}$ was for a long time disregarded as a serious possibility for a photovoltaically active material: as deposited $\mu \mathrm{c}-\mathrm{Si}: \mathrm{H}$ showed an undesired n-type doping which turned out to be detrimental for device operation. However, this could be overcome by microdoping [2, 3] and, more recently, by the purifier approach $[4,5]$. With the latter technique, viability of using $\mu \mathrm{c}-\mathrm{Si}: \mathrm{H}$ as an active PV-material was demonstrated by fabricating a $7.7 \%$ efficient singlejunction thin-film silicon solar cell [6]. Within the micromorph concept, where a stacked a-Si:H (gap $1.7 \mathrm{eV}$ ) / $\mu \mathrm{c}-\mathrm{Si}: \mathrm{H}$ (gap $1.1 \mathrm{eV}$ ) tandem structure allows a better use of the solar spectrum, a stable cell efficiency of $12 \%$ has been reported [7].

At present, the major concern of $\mu \mathrm{c}-\mathrm{Si}: \mathrm{H}$ is its low deposition rate $(1-2 \AA / s)$, combined with the thickness requirements $(\approx 3.5 \mu \mathrm{m})[5,7]$. Note that this situation which applies to intrinsic $\mu \mathrm{c}-\mathrm{Si}: \mathrm{H}$ is in contrast to the situation prevailing for the very thin doped $\mu \mathrm{c}$-Si:H layers which are used as contact layers in amorphous and other thin-film silicon solar cells [8].

When using hot-wire CVD, very high deposition rates up to $50 \AA / s$ for silicon ( $\mu \mathrm{c}-\mathrm{Si}: \mathrm{H}$ / poly-Si) have been reported [9]; this fact illustrates that high deposition rates should not be excluded a priori for $\mu \mathrm{c}-\mathrm{Si}: \mathrm{H}$. Indeed, encouraging first results on cells showed $3 \%$ conversion efficiency for the hot wire technique at a deposition rate of $5 \AA / s$ [10].

Within the field of plasma-enhanced CVD (PECVD), it has been shown that the VHF-GD technique, where the plasma excitation frequency is increased to the VHF-range, is very favourable for the growth of $\mu \mathrm{c}-\mathrm{Si}: \mathrm{H}$ [11-15]. On the other hand, early work by Matsuda in 1983 [16] demonstrated that for standard PECVD at 13.56 $\mathrm{MHz}$ plasma excitation frequency, pronounced hydrogen-dilution is not a necessary condition for $\mu \mathrm{c}-\mathrm{Si}: \mathrm{H}$ growth and can be compensated with high enough RF-power levels. However, deposition rates remained here below $1.5 \AA / \mathrm{s}$.

In this work it is shown that within the VHF-GD technique device-grade $\mu \mathrm{c}-\mathrm{Si} \mathrm{H}$ can be grown in excess of $10 \mathrm{~A} / \mathrm{s}$ by controlling the morphological phase transition thanks to the applied VHF-power, under restricted dilution levels.

\section{EXPERIMENTAL}

The i-layers both in the film and cell series were deposited at a VHF frequency of $130 \mathrm{MHz}$ and at a fixed dilution ratio of $7.5 \%$ silane/(silane+hydrogen). This dilution level is even under VHF conditions not sufficient (at low power levels) to allow for a morphological transition from the a-Si:H to the $\mu \mathrm{c}-\mathrm{Si}: \mathrm{H}$ phase [17]. To force the desired morphological transition towards the $\mu \mathrm{c}-\mathrm{Si}: \mathrm{H}$ phase, the applied VHF-power level was increased from 20 to $70 \mathrm{~W}$; this was measured by a directional power meter in the $50 \Omega$ line just before the matching network. The purifier technique $[4,5]$ was always applied when depositing the i-layers to avoid the incorporation of the detrimental oxygen contamination which usually results in n-type layers and, thus, in poor device performances. Other deposition parameters can be found elsewhere [18].

Under these conditions, about $2 \mu \mathrm{m}$ thick films were deposited on glass substrates (AF45 Schott) and on double-sided polished $<100>\mathrm{Si}$ wafers. On the former samples X-Ray diffraction was performed and on the latter samples the IR-absorption between 400 and $2500 \mathrm{~cm}^{-1}$ was determined in order to obtain insight both into the morphological transition and into the binding configuration.

Such intrinsic films were incorporated as active layers in $n$-i-p solar cells which were deposited on textured $\mathrm{SnO}_{2}$ coated glass (Asahi type $U$ ). As top contacts we sputtered ITO through a mask thus defining thereby the active solar cell area (diameter: $3 \mathrm{~mm}$ ). Simply a white sheet of paper was used as a back reflector, whilst doing current-tension (IV) and Spectral Response (SR) 
characterisations. This "test" configuration certainly does not lead to devices with the highest efficiencies, but it does allow for a fast and realistic probe of the layer quality. Furthermore, an immediate transfer on opaque substrates, such as aluminium, stainless steel, etc. is quite straightforward $[18,19]$.

The thickness measurement was done as close as possible to the active cell area with a surface profiler (Alpha Step 200 from Tencor Instruments). The cells have a thickness of $3.5 \pm 0.4 \mu \mathrm{m}$.

\section{RESULTS AND DISCUSSION}

\section{Layers}

Fig. 1 shows X-ray diffraction patterns of the films prepared at the fixed dilution of $7.5 \%$ but in function of the VHF-power level. At $20 \mathrm{~W}$ the absence of diffraction peaks reveals the growth of a-Si:H (confirmed by Raman and PDS). At higher VHF-power levels crystallites can be detected: the main diffraction peaks that can be observed are those for the $\langle 111\rangle,\langle 220\rangle$ and $<311\rangle$ orientations. One sees that it is indeed possible to control the morphology of the deposited layer by the applied VHF-power only. This is further confirmed by IRabsorption spectra as can be seen in Fig. 2: Typical "fingerprint" patterns at 640, 840, 880, 2000 and $2090 \mathrm{~cm}^{-1}$ pertaining to the bonding structure of a-Si:H can mainly be seen for the $20 \mathrm{~W}$ sample and become smaller and even disappear when going to higher VHF-power levels. At the same time, new and narrower peaks arise around 626, 900 and $2101 \mathrm{~cm}^{-1}$ (the latter 2 peaks are marked with thin vertical lines). These modes are different from those found for a-Si: $\mathrm{H}$ and are a clear indication for changes in the hydrogen bonding nature and in the bonding environment. Particularly, the modes around $2100 \mathrm{~cm}^{-1}$ are attributed to mono/dihydride bonds on $<100>$ and $<111>$ surfaces of silicon crystallites. Similar tendencies, both in X-Ray and in IR-spectra, have been shown elsewhere [20] for a dilution series.

For convenience, we have plotted in Fig. 3 the ratio of the intensities at $<220>$ and $<111>$. Whereas the silicon powder diffraction pattern (random orientation), reveals a ratio of 0.55 , in the films presented here this ratio can exceed 3.0 indicating a preferential growth along the $<220>$ axis (with a clear maximum around $50 \mathrm{~W}$ VHFpower).

The general trend that can be observed is that high hydrogen-dilution can indeed be replaced by substantially enhanced VHF-power levels. Restricted hydrogen-dilution (which results in higher deposition rates but hence also in a-Si:H growth if the dilution is not sufficient) can result in $\mu \mathrm{c}-\mathrm{Si}: \mathrm{H}$ growth if the applied VHF-power is high enough. From the data in Fig. 3 one may conclude, that the preferential growth along the $<220>$ axis is correlated with the appearance of mono/dihydride bonds on $<100>$ / $<111>$ surfaces of silicon crystallites (IR-absorption around $2100 \mathrm{~cm}^{-1}$ ). This is interesting in the context of the surface passivation properties that hydrogen shows on silicon [21, 22]. One may indeed raise the question whether we have here crystallites arranged vertically along the $<220>$ axis with surfaces (i.e. grain boundaries) where bonded hydrogen passivates dangling bonds.
Further work is, however, required to check the ideas suggested here.

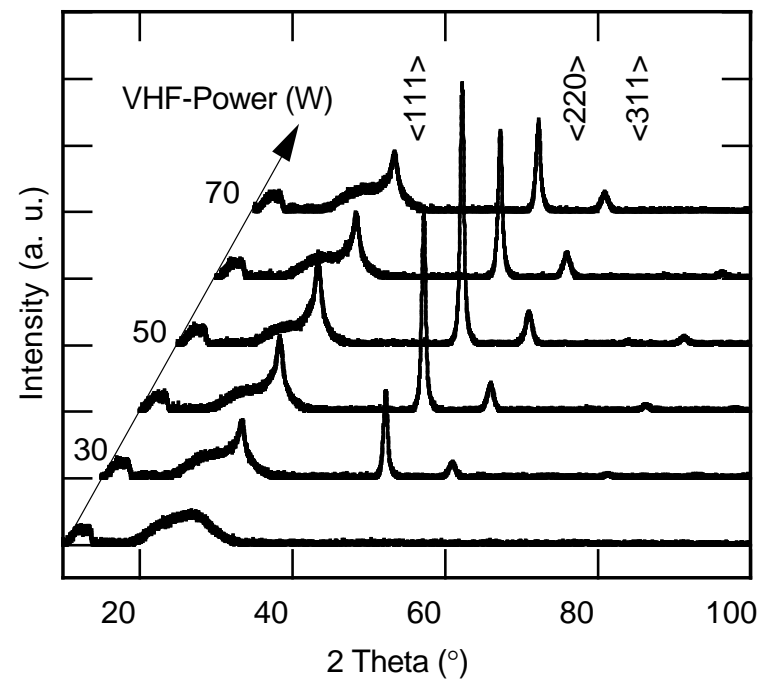

Fig. 1. X-ray diffraction pattern of layers deposited at a fixed dilution of $7.5 \% \mathrm{SiH}_{4} /\left(\mathrm{SiH}_{4}+\mathrm{H}_{2}\right)$. At a low VHFpower level of $20 \mathrm{~W}$ the morphology is amorphous, but at higher VHF-power levels we can clearly see an onset of crystalline growth.

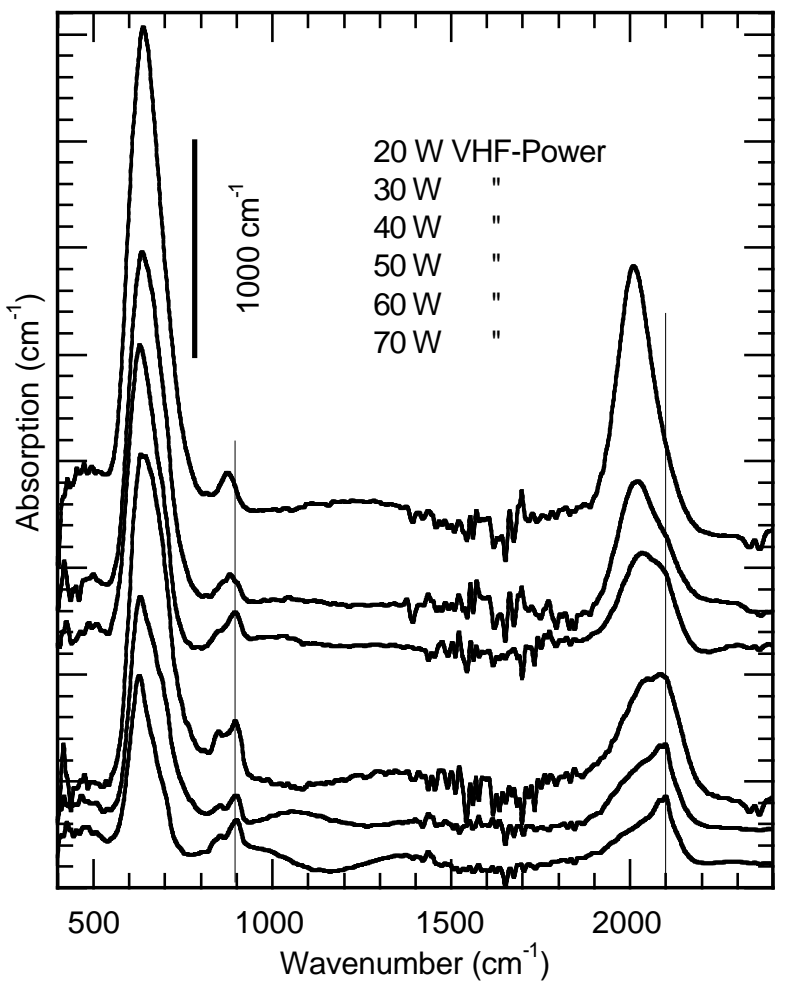

Fig. 2. IR-absorption spectra of layers prepared at different VHF-power levels as indicated in the figure. The spectra are vertically shifted for clarity. The fine vertical lines point to the absorption around 900 and $2100 \mathrm{~cm}^{-1}$ which can be associated to modes from mono/dihydride atoms on crystallite surfaces. 


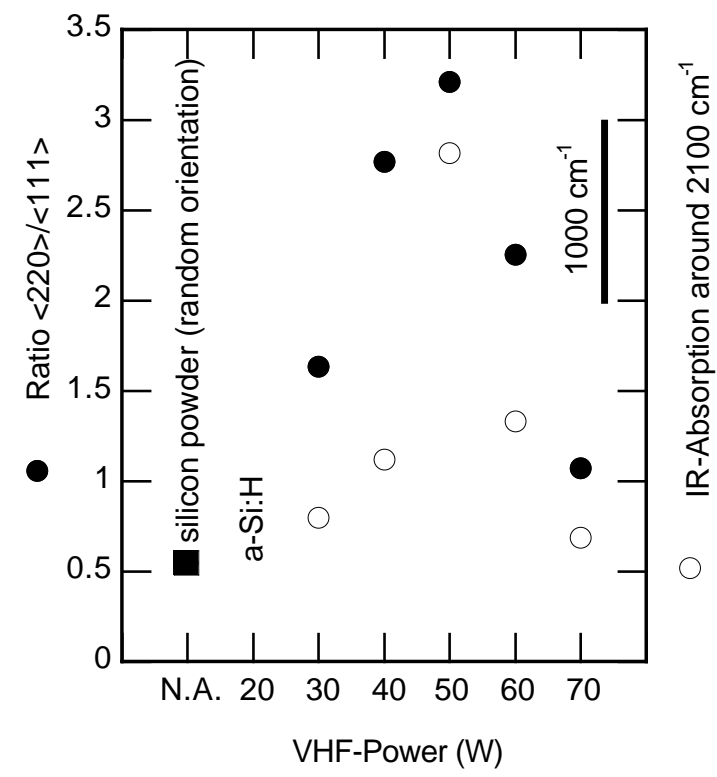

Fig. 3. Ratio of the $<220>/<111>$ X-Ray diffraction peaks for a silicon powder sample with random orientation and for the series presented here. Preferential growth along the $<220>$ axis is evident for all the layers, with a clear maximum around $50 \mathrm{~W}$. IR-absorption at $2100 \mathrm{~cm}^{-1}$ is also shown (stretching modes around $2100 \mathrm{~cm}^{-1}$ can be assigned to mono/dihydride bonds on $<100>/<111>$ surfaces of silicon crystallites).

\section{Solar Cells}

To investigate how this new series of $\mu \mathrm{c}-\mathrm{Si}: \mathrm{H}$ layers perform within an electrical device, complete n-i-p solar cell diodes were deposited incorporating the very same layers. In Fig. 4 we show deposition rates thereby obtained. A steady increase of deposition rate is observed by increasing the applied VHF-power. Unusually high deposition rates in excess of $13 \AA / s$ for $\mu \mathrm{c}-\mathrm{Si}: \mathrm{H}$ material is observed.

In Fig. 5a, b solar cell performances are given. Note that the structure employed has a specific advantage when growing the fully $\mu \mathrm{c}-\mathrm{Si}: \mathrm{H}$ cell. The thin window layer

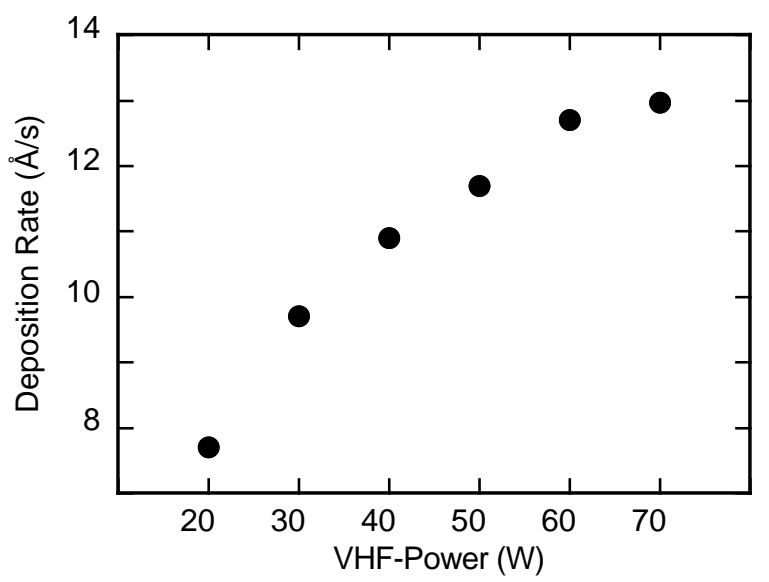

Fig. 4. Deposition rate of solar cells in function of the applied HF-power. (p-type $\mu \mathrm{c}-\mathrm{Si}: \mathrm{H}$ ) has a strong tendency to pick up the underlying morphology [23] and, thus, nucleates rather bad on a-Si:H (as is the case in the $20 \mathrm{~W}$ a-Si:H cell). A special nucleation pretreatment is required here [24]. This could also explain the increase in the fill factor for higher HF-powers, since nucleation is facilitated (on $\mu \mathrm{c}-\mathrm{Si}: \mathrm{H}$ ). Furthermore, in Fig. 5a a strong drop in Voc is observed for the cells deposited at higher VHF-power levels and can be explained by the optical gap of the corresponding materials; on the other hand, the low values obtained for both a-Si:H and $\mu \mathrm{c}-\mathrm{Si}: \mathrm{H}$-based cells in this series may be due to interface problems and do not necessarily reflect a Voc-limiting recombination in the bulk [7]. The strongest effect of $\mu \mathrm{c}-\mathrm{Si}: \mathrm{H}$ growth and structure on the solar cell performance can be seen from the obtained short circuit current. For this particular optimisation series the highest obtained conversion efficiency is $5.2 \%$ at a deposition rate of $10.9 \AA / \mathrm{s} \quad\left(\mathrm{Jsc}=21.8 \mathrm{~mA} / \mathrm{cm}^{2}, \mathrm{FF}=56 \%\right.$, Voc $=424 \mathrm{mV}$ ). In fact, this peak value is associated with an increase in the optical absorption of the incorporated material, as will be shown in detail in a future paper. Comparing Fig. 3 and Fig 5b, a remarkable correlation between the observed preferential growth along the $<220>$ axis, the IR-absorption around $2100 \mathrm{~cm}^{-1}$ and the short-circuit current (as well as the efficiency) of the resulting solar cells can clearly be observed.

a)
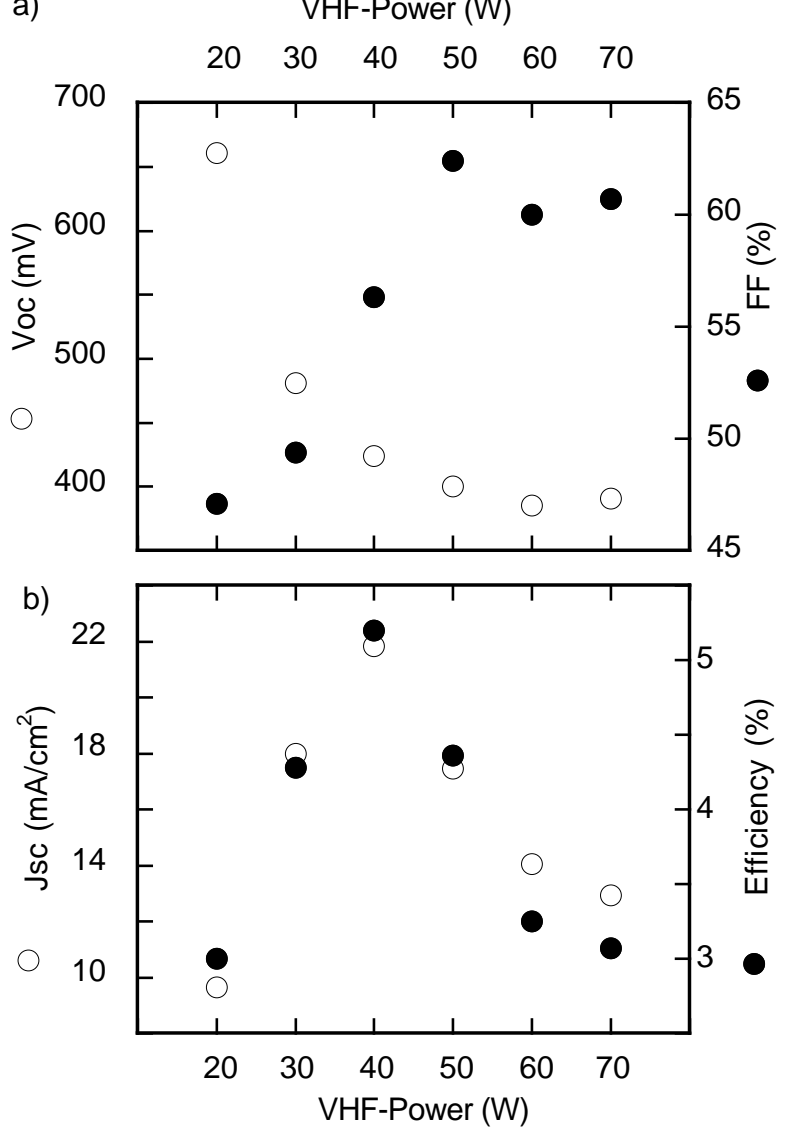

Fig. 5a, b. n-i-p solar cell performances after direct implementation of the i-layers which morphology is controlled by the HF-power only. 


\section{CONCLUSIONS}

Powder-free growth of a $\mu \mathrm{c}-\mathrm{Si}: \mathrm{H}$ solar cell at a deposition rate of $10.9 \AA /$ s with an AM 1.5 conversion efficiency of $5.2 \%$ is reported and, thus, illustrates that the VHF-GD deposition technique allows one indeed to obtain device-quality $\mu \mathrm{c}-\mathrm{Si}: \mathrm{H}$ material at reasonably fast deposition rates.

It is shown that it is possible to control the morphological transition from a-Si:H to $\mu \mathrm{c}-\mathrm{Si}: \mathrm{H}$ under a restricted hydrogen-dilution by the applied HF-power only. By that the deposition rate can be increased up to $13 \AA / s$.

An interesting correlation tendency is found between the preferential growth of the crystallites in the <220> direction, the IR-absorption around $2100 \mathrm{~cm}^{-1}$ and the final $\mu \mathrm{c}-\mathrm{Si}$ :H solar cell efficiency.

The authors suspect that this is mainly due to light scattering effects which enhance the effective optical absorption in the near infrared. Investigating this link should be the scope of future work.

\section{ACKNOWLEDGMENTS}

The technical assistance of S. Dubail is gratefully acknowledged. This work was supported by the Swiss Federal Office for Education and Sciences under Research Grant 96.0340.

\section{REFERENCES}

[1] S. Veprek and V. Marecek, "The Preparation of Thin Layers of Ge and Si by Chemical Hydrogen Plasma Transport," Solid-State El., Vol. 11, 1968, p. 683-684.

[2] C. Wang and G. Lucovsky, "Intrinsic Microcrystalline Silicon Deposited by Remote PECVD: A New Thin-Film Photovoltaic Material," 21IEEE Photovoltaic Specialists Conference, Vol. 2, 1990, p. 1614-1618.

[3] R. Flückiger, et al., "Electrical Properties and Degradation Kinetics of Compensated Hydrogenated Microcrystalline Silicon Deposited by VHF-GD," J. Appl. Phys., Vol. 77, 1995, p. 712-716.

[4] U. Kroll, et al., "Origin and Incorporation Mechanism for Oxygen Contaminants in a-Si:H and $\mu \mathrm{c}-$ Si:H Films prepared by the Very High Frequency (70 $\mathrm{MHz}$ ) Glow Discharge Technique," Mat. Res. Soc. Symp. Proc., Vol. 377, 1995, p. 39-44.

[5] P. Torres, et al., "Device Grade Microcrystalline Silicon Owing to Reduced Oxygen Contamination," Appl. Phys. Lett., Vol. 69, 1996, p. 1373-1375.

[6] J. Meier, et al., "On the Way towards High Efficiency Thin-Film Silicon Solar Cells by the "Micromorph" Concept," Mat. Res. Soc. Symp. Proc., Vol. 420, 1996, p. 3-14.

[7] J. Meier, et al., "Recent Progress in Micromorph Solar Cells," to be published in Journal of Non-Crystalline Solids (ICAMS 17), 1997.

[8] R. Flückiger, et al., "Preparation of Undoped and Doped Microcrystalline Silicon ( $\mu \mathrm{c}-\mathrm{Si}: \mathrm{H}$ ) by VHF-GD for p-i-n Solar Cells," 23IEEE Photovoltaic Specialists Conference, 1993, p. 839-844.

[9] A. R. Middya, et al., "Fast Deposition of Photoconductive Polycrystalline Silicon by Hot-Wire
CVD," Mat. Res. Soc. Symp. Proc., Vol. 377, 1995, p. $119-124$.

[10] J. K. Rath, et al., "Purely Intrinsic Poly-Silicon Films by Hot-Wire CVD," Mat. Res. Soc. Symp. Proc., Vol. 452, 1997, p. 977-982.

[11] K. Prasad, PhD-Thesis, "Microcrystalline Silicon $(\mu \mathrm{C}-\mathrm{Si}: \mathrm{H})$ prepared with Very High Frequency Glow Discharge (VHF-GD) Process," Institut de Microtechnique de I'Université de Neuchâtel, Neuchâtel 1991.

[12] P. Hapke, et al., "Large Grain Size and High Deposition Rate for Microcrystalline Silicon Prepared by VHF-GD," Mat. Res. Soc. Symp. Proc., Vol. 358, 1994, p. 745-750.

[13] F. Finger, et al., "Improvement of Grain Size and Deposition Rate of Microcrystalline Silicon by Use of VHF-GD," Appl. Phys. Lett., Vol. 65, 1994, p. 2558.

[14] R. Flückiger, et al., "Structural and Electrical Properties of Undoped Microcrystalline Silicon Grown by $70 \mathrm{MHz}$ and 13.56 MHz PECVD," Mat. Res. Soc. Symp. Proc., Vol. 358, 1995, p. 751-756.

[15] P. Torres, et al., "Enlarged Parameter Space by Use of the VHF-GD for Deposition of Thin p-type $\mu \mathrm{c}-\mathrm{Si}: \mathrm{H}$ Films," Mat. Res. Soc. Symp. Proc., Vol. 453, 1997, p. 767-772.

[16] A. Matsuda, "Formation Kinetics and Control of Microcrystallite in $\mu \mathrm{c}-\mathrm{Si}: \mathrm{H}$ from Glow Discharge Plasma," J. of Non-Cryst. Solids, Vol. 59\&60, 1983, p. 767-774.

[17] N. Beck, et al., "Optical and Electrical Properties of Undoped Microcrystalline Silicon Deposited by the VHF-GD with Different Dilutions of Silane in Hydrogen," Mat. Res. Soc. Symp. Proc., Vol. 452, 1997, p. 761-766.

[18] P. Torres, et al., "Microcrystalline Silicon Solar Cells at Higher Deposition Rates by the VHF-GD," Mat. Res. Soc. Symp. Proc., Vol. 452, 1997, p. 883-888.

[19] M. Goetz, et al., "n-i-p Micromorph Solar Cells On Aluminium Substrates," Mat. Res. Soc. Symp. Proc., Vol. 452, 1997, p. 877-882.

[20] U. Kroll, et al., "From Amorphous to Microcrystalline Silicon Films Prepared by Hydrogen Dilution Using VHF-GD (70MHz)," Journal of NonCrystalline Solids (ICAMS 17), 1997.

[21] N. Beck, et al., "Enhanced Optical Absorption in Microcrystalline Silicon," J. of Non-Cryst. Solids, Vol. 198200, 1996, p. 903-906.

[22] M. A. Green, High Efficiency Silicon Solar Cells. Aedermannsdorf: Trans Tech SA, 1987, ISBN 0-87849537-1.

[23] P. Torres, et al., "Very Low Temperature Epitaxial Growth of $<\mathrm{p}>$-type Silicon for Solar Cells," 13th EC PVSEC, 1995, p. 1638-1641.

[24] P. Pernet, et al., "Growth of Thin $<p>\mu c-S i: H$ on Intrinsic a-Si:H for <nip> Solar Cells Application," Mat. Res. Soc. Symp. Proc., Vol. 452, 1997, p. 889-894. 